\title{
How Close are We to a COVID-19 Vaccine?
}

\section{Kayhan Ozkan}

Department of Physiology, Medical School, Duzce University P.O. 81620, Konuralp, Duzce, Turkey.

\begin{abstract}
This review provides an overview regarding the main aspects of candidate COVID-19 vaccines and pathophysiology of disease. The types of biotechnological candidate vaccines to be developed against COVID-19, their degree of protection and the pathophysiological mechanism of the disease were analyzed in this review article. The literature data on which cruxes for the development of biotechnological candidate vaccines to be wended are based was researched. Data that could give reference to various biotechnological candidate vaccines were reviewed. For this purpose, up-todate literature data was utilized. The ways to succeed in the development of a vaccine requiring a technological infrastructure are to synthesize the data obtained from long term trials and to put them into practice subsequently. The vaccines to be developed by means of recombinant DNA technology will be a source of inspiration to people for further studies. After a rapid process of vaccine development, the use of COVID-19 vaccine can be mainstreamed among people to prevent the disease. As a result of these practices, the evaluation of which vaccine will be more safe, reliable and effective will be performed after phase studies.
\end{abstract}

Keywords: COVID-19 vaccine, recombinant, atteneu virus, immune response, phase studies

*Correspondence: kayhanozkan@hotmail.com; +90 5353601230

(Received: April 23, 2020; accepted: May 02, 2020)

Citation: Ozkan K. How Close are We to a COVID-19 Vaccine?. J Pure Appl Microbiol. 2020;14(suppl 1):893-902. doi: 10.22207/ JPAM.14.SPL1.26

C The Author(s) 2020. Open Access. This article is distributed under the terms of the Creative Commons Attribution 4.0 International License which permits unrestricted use, sharing, distribution, and reproduction in any medium, provided you give appropriate credit to the original author(s) and the source, provide a link to the Creative Commons license, and indicate if changes were made. 


\section{INTRODUCTION}

An infection being detected for the first time in a patient applying to hospital with pneumonia complaint on $17^{\text {th }}$ of December 2019 in China (Hubei-Wuhan) was defined as COVID-19 (SARS-CoV-2 Infection) in the first half of December. ${ }^{1}$ In the last month of 2019, an increase appeared in the number of people applying to health centers having a suspicion of respiratory disease. World Health Organization declared this epidemic as pandemic on March $11,2020 .^{2}$ When the declaration of WHO arouse, there were 118.000 cases and more than 4.000 deaths across the globe. The infection affected all countries around the world for several months and leading to over sudden deaths. Propagation and contagion velocity of the virus among people is more aggressive compared to other viral origins having been diagnosed so far.

Pathophysiology of COVID-19

Clinical symptoms of the patients getting infected have been observed as fever (88.5\%), cough (68.6\%), muscle pain or fatigue (35.8\%), expectorating $(28.2 \%)$ and shortness of breath (21.9\%). It has been reported that there were some cases with losses in olfactory perception as well. ${ }^{3}$ The root cause of shortness of breath depends on the damage developed in the defense system by lungs' alveoli due to the viral protein. ${ }^{4}$ This damage is quoted as "Cytokine Storm" appearing as a result of the mechanisms of defense system formulating defect in body cells. ${ }^{5}$ This damage deteriorates gas transfer and shortness of breath develops in the affected patients. When viruses enter into a living organism, they live and replicate inside a living host to be able to survive. Another feature of viruses is that they move into the organs which are away from the colonized tissues through neural networks. This notion, ranked as "retrograde axonal transport" in the literature, makes us ask this question to ourselves: Can corona COVID-19 virus affect the respiratory center in the brain through retrograde transfer? Scientists observed on electron microscope that fake rabies viruses move into GABAergic parasympathetic nerves in this way. ${ }^{6-7}$ The controversy issues in pathophysiology of this disease may result in death as clinical symptoms get severe need to be construed.
Another condition of COVID-19 disease in pathophysiology is the migration route to lungs of pathogens taken into the body. It was observed in the studies that it clings to the ACE-2 receptors in lungs' alveoli through Spike protein on SARS-CoV-2. ACE-2 acts as a host cell receptor for SARS-CoV by clinging to Spike protein on viral capsid. The clinging of Spike protein to ACE-2 triggers the activation of ADAM 17 enzyme and it may commence the activity for reducing the amount of ACE-2. ${ }^{8}$ The virus gene passes into the sarcoplasm and RNA increases with RNA polymerase. ${ }^{9}$ Then, with exocytosis, it comes out from the cell membrane with vesicles again. ${ }^{10}$ The alveolar cell was damaged during the exocytosis phase. ${ }^{11}$ Alveolar macrophages detect the damaged cell. TNF alpha triggers the production of IL-1, IL-6, IL-8, initiating the inflammation phase. ${ }^{12}$ The proinflammatory cytokines TNF alpha and IL-1 increases vascular permeability. ${ }^{13}$ IL-8 stimulates the neutrophils to increase it and cytokines increase and edema in the interstitial space is shaped. ${ }^{14}$ This pulmonary edema leads to developing hypoxia. The emergence of this acute phase reaction has been called acute respiratory distribution syndrome. ${ }^{15}$ Today, effective medicines in these pathways have been utilized in order to prevent inflammation. ${ }^{16}$ The development of pneumonia fact depends on a range of immune responses transpired in alveoli. This response stimulates $T$ lymphocytes after the production of macrophages and plasma cells. Subsequently, macrophages, monocytes and neutrophils mobilize for inflammation. As a result of these, the process called "Cytokine Storm" intercedes and it results in a condition eventuating with pneumonia (Fig. 1).

Medicines are utilized in people having COVID-19 disease for treatment in different countries in the world but these treatments are symptomatic. The most crucial and determinant factor for prevention of the disease and virulence decrease of the virus around the world is constituted of vaccine efforts. Various biotechnology companies making efforts to develop preclinical vaccines across the globe have started to work. ${ }^{17}$ In this review article, the COVID-19 candidate vaccines under development are inspected. The period from production to the 


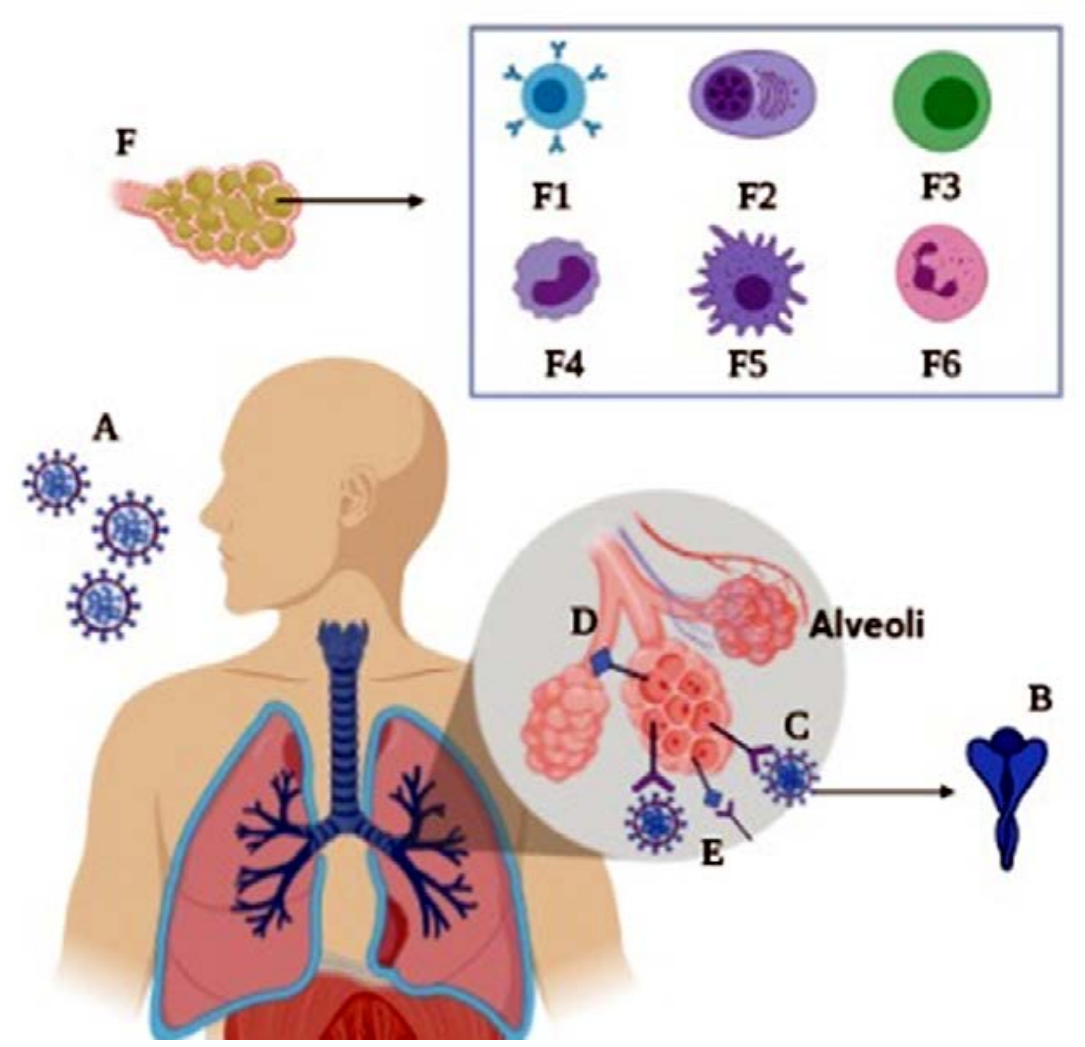

Fig. 1. Immune response causing pneumonia in alveoli is shown. A: SARS CoV-2 aerosol taken, B: Coronavirus spike protein, C: binding to ace 2 receptor with coronavirus spike protein, D: ADAM 17 receptors are activated, trying to reduce the number of ACE 2. B-lymphocytes (F1), plasma cells (F2), T cells (F3), monocytes (F4), macrophage (F5), neutrophil (F6) provides "cytokine storm". F: The development of pneumonia following the cellular defense mechanism.

utilization of the vaccine that is to be developed for the disease has been expedited. Firstly, all candidate vaccine developers need preclinical trials by ensuring the discovery of antigen. They are to obtain quality control documents of approval such as Good Manufacturing Practices (GMP), Good clinical practice (GCP), Food and Drug Administration (FDA) after the vaccine's immune efficiency, stability and toxicity are investigated and found to be convenient. After the completion of phases of $1,2,3$ and 4 , it is to be brought into use. A way of accelerating the development of vaccine is to originate from vaccine development technologies being utilized at present and to build on the efforts of current vaccines that might have passed clinical efforts successfully. For instance, a vaccine for H1N1 pandemic influenza was brought into common use in only six months following the recognition of new influenza strain in 2010 because this pandemic vaccine was identical to the vaccines being utilized for the prevention from prior seasonal influenza strains. Additionally, a significant progress was achieved in the development of vaccines against infections in the last two major Coronavirus pandemics, first in 2003 Severe Acute Respiratory Syndrome (SARS) and later in 2012 for Middle East Respiratory Syndrome (MERS). Researchers now use a part of these efforts as base in order to expedite the progress of vaccine development against COVID-19.

Vector-based vaccine

Coronavirus is surrounded by thorn surfaced glycoproteins and it is situated in lipid envelope. As a consequence of this feature, it has epitopes inducing neutralizer antibodies in host. Spike protein is produced by the virus in an inartificial infection. Therefore, the disease- 
causing properties of the spike protein to be used in the candidate vaccine intended to initiate immunization should be well evaluated. Spike proteins in recombinant vaccines, just as DNA, RNA or subunit vaccines, may not be exactly same. Accordingly, these vaccines generally cannot stimulate local immunity enough or they might be required to be inoculated again to ensure complete protection. Making modifications in the genome of a pathogenic virus to develop a reliable, enervated and lively Coronavirus vaccine that can induce immune reaction is a complicated process. ${ }^{18}$

Certain vector- based viral origins were utilized during vaccine development efforts. Studies in the past years aimed at procuring immunization against diseases generated by viral origins through the utilization of adenovirus vector-based vaccines. Adenovirus vector-based vaccines have been being developed against influenza virus, HIV and Ebola virus as well as some other infectious diseases. Today, AdHu5 vector-based HIV Adenovirus vaccines are being developed within the scope of fighting HIV. This vaccine is designed to function by coding gag, pol and env genes. It is tested on 1.494 volunteers and 1.506 people are determined as placebo group. It was planned to lighten the viral load in order to induce CD8 T cells but it was not succeeded.$^{17}$ In addition to this, other serotypes as AdHu26 and AdHu35 were rather preferred due to the fact that AdHu5 vector-based vaccines are not applicable for HIV treatment; however, they have not attained a place in the market yet. Nevertheless, adenovirus type- 5 vector-based vaccines are estimated to be developed against COVID-19 disease. Today, researchers conducting studies on mRNA vectorbased vaccines have just reached to the phase one. There are 45 volunteers aged between 1855 for the study on mRNA-1273. The chance of success will be analyzed in the future when phase one studies eventuate. Nonetheless, this success increases in direct proportion to biotechnological advancements along with the protection of patients from the disease by stimulating immunologic mechanisms of antigens. ${ }^{19}$ Adenovirus vectorbased vaccines has been being utilized to protect animals from diseases for several years. Some types of adenoviruses are mammalian cell expression vectors which avail potentially as living recombinant vaccines and they are crucial for high level of antibody production. An enervated adenovirus vector-based vaccine containing Ad4

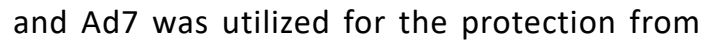
acute respiratory tract infections (SARS and MERS) to that end . ${ }^{20}$ Developing an ideal vaccine for mucosal surface pathogens such as COVID-19 must have the feature of inducing the systemic immune system. In vivo systemic and mucosal antigen specific immune responses of recombinant adenoviral type 5 (Ad5) based candidate vaccines expressing Coronavirus protein ( $\mathrm{S}$ ) that are induced by intragastric or intramuscular single dose implementation are found to be promising by the researches. ${ }^{21}$ Adenovirus with viral vector vaccine development efforts have been made in the recent past in order to analyze its effectiveness of protection from H3N2 influenza virus infection. After the implementation of this vaccine with the aim of prime-boost, it was observed that the response of IFNY was induced. Thus, viral titers infected by the influenza virus in the respiratory tracts of ferrets decreased. In general, these results have developed our understanding of development of a vaccination, which can resort to both cellular and humoral immunity, for the purpose of development of a global influenza virus vaccine. ${ }^{22}$ On the other hand, there was an evaluation of viral immunogen hemagglutinin in another study that analyzed vector-based vaccines developed against influenza virus. The most crucial point of these is that viral hemagglutinin is required to be updated in the period of vaccine development annually. The most significant advantage of vector-based vaccines is that they pledge long-term immunity without the necessity of an additional implementation. ${ }^{23}$ In a study on cell culture, it was observed that nonstructural protein 1 of mouse hepatitis virus reduced cellular gene expression robustly just as SARS-Coronavirus homolog does; however, a limited replication in lymphoid organs was observed as well. ${ }^{24}$

In the Coronavirus infection murine model, the impact of nonstructural protein 1 on pathogenicity was analyzed. The virus eliminated a part of this protein. Yet, scientists procreated a recombinant virus enervated with in vivo by this way. Thus, virus protected its ability to reproduce in cells and this may meet a significant part of a promising candidate COVID-19 vaccine development requirement. The most crucial 
features of a candidate COVID-19 vaccine to be developed are to be protective, long-term and stimulating antigen specific cellular immunity. A candidate COVID-19 vaccine could be developed with a purpose of acquiring a mechanism that grounds on the configuration of a similar immune response. The pathophysiology and virulence mechanisms of SARS-CoV-2 in human body have connection with the functions of nonstructural proteins. Nonstructural proteins are essential components of replication and transcription complex. Studies revealed that these proteins Coronaviruses have may prevent innate adaptive immune response. ${ }^{25}$

Increscent symptoms of COVID-19 has been observed at the stage of pneumonia. The exchange of blood gases becomes difficult as a result of pathogenic mechanism in lung alveoli. Tissues affected by the virus are damaged. Presumptive mechanism responsible for this damage arises as a result of the body's effort to protect itself. To exemplify, it causes an increase in the number of interleukin 6 cytokine and it generates wide tissue damages. Additionally, it equilibrates the balance of $\mathrm{T} 1$ and $\mathrm{T} 2$ cells. Lymphocytes cause changes of certain cell size by variance and they stimulate thermoregulation mechanisms through stimulating acute phase protein production. Although the main role of IL-6 is proinflammatory, it may have anti-inflammatory effects as well. The appearance of these effects depends on the virulence of the virus and the part of the organ it holds on to. ${ }^{26}$ On the other hand, some viral vector-based vaccines may increase Immunogenicity without an adjuvant and they may induce a strong cytotoxic T-lymphocytes response. A candidate COVID-19 vaccine might have similar vector features with formerly developed MERS-Cov and SARS-Cov vaccines. A recombinant modified vaccine virus expressing MERS-CoV S protein, Ankara (MVA), developed a high level of specific neutralizer antibody response in intramuscular vaccinated mice. Studies indicated that this intramuscular or subdermal vaccine utilized for vaccine implementation provided a high level of protection against MERS-CoV and SARS-CoV infections. ${ }^{27}$ Consequently, a counterpart effect might give favorable results in pathophysiology appearing during COVID-19 infection.

\section{m-RNA and DNA Candidate Vaccines}

DNA vaccines were first planned to be developed against influenza disease. It was revealed in preclinical studies that this vaccine promoted protective antibodies against influenza virus. After these premise studies, DNA vaccine development efforts for cancer studies proceeded. The vaccine, being non-viable, eliminates the infection development risk in the vaccinated person. They are easily producible and with highlevel stability groups of vaccines. It was deduced from these clinical studies after this process that DNA vaccines are reliable. ${ }^{28}$ Today, lots of DNA vaccines are under development.

It is critical to detect the target antigen in DNA vaccine development. In silico analysis of genomic, proteomic and transcriptomic data should be performed. DNA vaccine was developed for toxoplasma gondii vaccine on the basis of these procedures. ${ }^{29}$ According to the information published, WHO announced that Spike glycoprotein, Li key peptide, gp-96, M protein and NK protein-based DNA vaccines are under development.

Genetic row of COVID-19 was published in public access databases by Shanghai Public Health Clinic Center and Public Health School in $10^{\text {th }}$ January $2020 .{ }^{30}$ Conformational three-dimensional structure of Spike protein demonstrated that it clings to human cell surface receptors more tightly than SARS-CoV and it was claimed that this might be a probable reason of this Coronavirus producing more infectivity. ${ }^{31}$

COVID-19 vaccine of candidate mRNA1273 in this group is to be inoculated on 45 volunteers with three different dosages (25, $100,250 \mu \mathrm{g})$. The volunteers will be surveilled and its reliability and Immunogenicity will be investigated. The vaccines in these groups may formalize responses having similar features with SARS-CoV derivative epitopes corresponding to SARS - CoV - 2. There is a need for more evidence to search about vaccines developed for inducing protective $T$ cell response revealed to provide long-term protection from SARS-CoV. SARS-CoV derivative linear B cell epitopes in $\mathrm{S} 2$ subunit might be potentially more promising candidates for inducing a protective antibody reaction. This group of vaccine development efforts have increased 
the potential significance of former experimental and clinical SARS-CoV studies in general. Along with the data arouse for SARS-CoV, they act as a guideline for the research of effective vaccines against COVID-19 pandemic. $^{32}$

\section{Protein-based Vaccines}

These vaccines are built upon molecular clamp technology. They imitate protein conformation on a live virus and create a strong immune reaction by stabilizing the pre-fusion form of viral fusion proteins. This method is utilized to develop subunit vaccines against Class I and III enveloped viruses. A polypeptide is used in order to protect pre-fusion structure and to prevent its reproduction after the protein penetrates into the cell. ${ }^{33}$ They were utilized to produce chimeric polypeptides imitating the prefusion conformations of some enveloped viruses before. The aim is to complete the preclinical developments in 16 weeks, then to proceed directly to Phase 1 clinical studies by finalizing this stage in 10 weeks and large-scale production of more than 200.000 dosages in 8 weeks. ${ }^{34}$ This study approved that the conceived vaccine candidate is easily recognized by immunity system and stimulated a protective immune response..$^{35}$

Protein-based vaccines are constituted of a more traditional approach involving only protein injection of the virus. These proteins are $S$ proteins on the surface of Coronavirus and nucleocapsid replications. These proteins act indecisive on their own and lose their shape after the injection rapidly which makes it challenging for the immune system to produce antibodies peculiar to the virus. However, researchers have developed a "molecular handcuff" which helps viral proteins to preserve their shape and immune system to elicit a reaction. Along with this principle, human papillomavirus vaccines have induced immunity by connecting to the free surface proteins before and this overall approach has given promising results. ${ }^{36}$ A conventional vaccine consists of biological agents with reduced effectiveness or including inactive viruses. Spike protein-based vaccines having utilized for Hepatitis B vaccines as a counterpart method are under development. The vaccine may succeed if a method that can neutralize the $S$ protein part of the virus is implemented. These are neutralizer antibodies by which cells are prevented from infections by the viruses. Monoclonal antibodies were produced by Chinese hamster ovary ( $\mathrm{CHO}$ ) cells by this method in the previous years. Active ingredients utilized for this aim are antigens with glycan produced in $\mathrm{CHO}$ cells. Antigens without glycan are acquired by being produced in yeast cells. ${ }^{37}$ For this purpose, they are to neutralize them by preventing Spike proteins on virus' surface from clinging to ACE2 receptor cells.

\section{Inactive Candidate Vaccines}

Inactivated virus is composed of virus particles that are produced in culture and have lost their capacity to cause a disease. Pathogens for inactive vaccines are grown under control and they get killed as a tool in order to decrease virulence so that an infection from the vaccine can be prevented. Virus to be utilized for the vaccine become inactivated by using methods such as heat or formaldehyde. Inactive vaccines are classified according to the methods utilized for inactivation. The potential success of COVID-19 candidate inactive vaccine may be referenced to the researches on SARS vaccine. An inactive vaccine for Severe Acute Respiratory Syndrome (SARS) in relation to Coronavirus (SARS-CoV) in Rhesus monkeys was analyzed in a study. Monkeys were inoculated with $0.5,5,50$ or 5000 mikrog or controlled intramuscular (i.m.) PBS. Three weeks later, NS-1 was challenged with SARS-CoV strain. The results showed that the inactive vaccine can induce immunity against SARS-CoV infection. In addition, the same study revealed that the vaccine is safe in monkeys and may be demonstrate for clinical trials. ${ }^{38}$ Nonetheless, another study indicated that the vaccine underperformed in aged animal models in which diploid inactivated vaccines were inoculated. This vaccine was inoculated both adjuvanted and nonadjuvanted. In the study, it was revealed that eosinophilic immune pathology was observed in the aged animals' lungs and they were not able to be protected against virus replication. These data magnify the concerns about the reliability of inactive vaccines and emphasize the necessity for further studies so as to resolve molecular mechanisms controlling the failure of the vaccine and eosinophils induced particularly in COVID-19 disease. $^{39}$ 


\section{CONCLUSION}

COVID-19 approximates to the third biggest epidemic in 20 years caused by Coronaviruses, but its place in this ranking is not clear yet since the pandemic is still continuing. Patients died of this disease had chronic medical illnesses progressing with comorbidity. It was observed that $6.7 \%$ of SARS patients had acute renal failure, $84.6 \%$ of them had proteinuria. ${ }^{40}$ Complications faced with SARS-CoV-2 are acute respiratory failure $29 \%$, anemia $15 \%$, acute cardiac injury $12 \%$ and secondary infection $10 \% .{ }^{41}$ It was reported in a study that 11 of 99 COVID-19 patients died of multi-organ failure and 7 of them were above $60 .{ }^{42}$ Influenza vaccines developed with today's technology are required to be renovated yearly due to differentiation in conformational structure of surface $S$ proteins of virus. The most essential weapon among fighting strategies with a pandemic disease is vaccine inoculations. In this review article, general features of vector, mRNA and protein-based candidate vaccines under development against COVID-19 disease were examined. The most effective way of fighting against a pandemic is possible with vaccination. The success chance of candidate COVID-19 vaccine will be evaluated with its protection in cases which cause of disease is experienced regardless of the method the vaccine is developed.

Studies represent the propagation velocity of a virus with $R_{0}$ (reproduction number) value. This value helps us predict an average number of people infected by a single person. This value was reported as nearly 1.3 for influenza virus. While studies on calculating $R_{0}$ value of COVID-19 have been still progressing, this value has been calculated as 2.2 since the end of January, which means that an infected person can infect 2.2 people more. In addition to this, researchers have calculated 12 different estimated $R_{0}$ values of the virus. According to these estimations, $R_{0}$ value of the virus ranges between 1.8 and 3.3. This number is apt to change depending on the factors such as the frequency of contacts people come into with one another and efforts of decreasing virulence spread. It was reported that the number of new people who are apt to be infected by each person should be under 1 to be able to end a pandemic. ${ }^{43}$ This demonstrates that both the viral originated diseases indicate more rapid spread and quarantine precautions should be expanded. Thus, we can deduce that the timing of phase studies completion and release of candidate vaccines to be developed are of vital importance.

Vaccine developer companies have been using vector-based vaccines for animals for many years. For instance, recombinant vaccines utilized for poultries against Newcastle disease are classified in this group. These Marek virus-based vaccines decreased the dispersion of viral origin and ensured protection against the disease..$^{44-45} 4$ DNA vaccines and immune therapy products were certified for various species including salmon, pig, dog and horse in the scope of application of veterinary medicine in the last 15 years. These products were the first vaccines commercially certified by DNA vaccine platforms and they initiated robust advancement in biotechnology. ${ }^{46}$ Besides, immune complex vaccines stimulating B lymphocytes and providing protection to chicken against IBDV have been being utilized for several years. The vaccines in these groups were developed by mixing infectious bursal disease virus (IBDV) with hyperimmune IBDV chicken serum. ${ }^{47-48}$ We can draw a parallel between this method and entreating COVID-19 patients with the plasma obtained from the people who were infected and regained their health. Counterpart vaccine development methods as hyper immune serum can be utilized for development of a COVID-19 vaccine. It was observed in a study conducted in China that immunoglobulin treatment administered to 10 patients, who were not at inflammation stage yet but whose oxygenations decreased, and viral load diminished. ${ }^{49}$ Apart from vaccination, some other factors such as health policies of the country, quarantine precautions, age average of people, per capita income are to have an influence on protection from the disease.

On the other hand, vaccines used in poultry are live ateneu vaccines and have been used for many years. In addition, Coronavirus vaccines are used against infectious bronchitis diseases of commercial poultry. ${ }^{50}$ These vaccines provide homologous protection against poultry Coronavirus types but are not sufficient for more than one serotype. ${ }^{51}$ Because there are many Coronavirus serotypes in poultry. ${ }^{52}$ Therefore, protection against bronchitis is provided by the combination of vaccines containing 2 different 
strains. ${ }^{53}$ The COVID-19 vaccine has a single serotype, but it mutates over time. It is clear after phase studies how the isolated vaccine virus will create an immune level against this change.

Vaccine production cycle lasts more than 70 weeks. ${ }^{54}$ Producers and authorities are to be obliged to administer innovative approaches to minimize delays in a state of emergency. Along with this, producers and authorities should cooperate in order to provide required dosages when they face with a massive and emergent vaccine necessity. Vaccine development process has long-continued stages. Concurrent utilization demand may arise in world countries after the completion of these stages. Clinical and serologic studies might be required in order to verify which populations are at the highest risk and a procedure can be developed to create a fair vaccine allocation system globally.

First of all, we need to analyze the effect and actions of the virus in host. Initially, an animal model is required to be able to achieve this. It must be ensured that the potential vaccine is reliable and it stimulates immune system properly without damaging the body. After all of these processes, the vaccine is to be brought into use after the vaccine is confirmed to be reliable and effective.

\section{ACKNOWLEDGMENTS}

None.

\section{FUNDING}

None.

\section{ETHICS STATEMENT}

This article does not contain any studies with human participants or animals performed by any of the authors.

\section{AVAILABILITY OF DATA \\ Not applicable.}

\section{REFERENCES}

1. Wu Z, McGoogan JM. Characteristics of and important lessons from the coronavirus disease 2019 (COVID-19) outbreak in china: summary of a report of 72314 cases from the Chinese center for disease control and prevention. JAMA. 2020;323(13):1239-1242. https:// doi.org/10.1001/jama.2020.2648.

2. World Health Organization (WHO), 2020. Virtual press conference on COVID-19. Available at: https:// www.who.int/docs/default-source/coronaviruse/ transcripts/who-audio-emergencies-coronaviruspress-conference-full-and-final-11mar2020.pdf?sfursn =cb432bb3_2 [Last Accessed date: 30 April 2020].

3. Wuab Y, Xuc X, Chen Z, et al. Nervous system involvement after infection with COVID-19 and other coronaviruses. Brain Behav Immun. 2020;3:889-1591. https://doi.org/10.1016/j.bbi.2020.03.031

4. Zhang $\mathrm{H}$, Penninger JM, Li Y, Zhong N, Slutsky AS. Angiotensin-converting enzyme 2 (ACE2) as a SARS-CoV-2 receptor: molecular mechanisms and potential therapeutic target. Intensive Care Med. 2020;46(4):586-590. https://doi.org/10.1007/s00134020-05985-9

5. Mehta P, McAuley DF, Brown M, et al. Covid - 19: consider cytokine storm syndromes and immunosuppression. Lancet. 2020;395(10229):10331034. https://doi.org/10.1016/S0140-6736(20)306280

6. Stornetta RI, Mcquiston TJ, Guyenet PG. GABAergic and glycinergic presympathetic neurons of rat medulla oblongata identified by retrograde transport of pseudorabies virus and in situ hybridization. $J$ Comp Neurol. 2004;479:257-270. https://doi.org/10.1002/ cne. 20332

7. Antinone SE, Smith GA. Retrograde axon transport of herpes simplex virus and pseudorabies virus: a live-cell comparative analysis. J Virol. 2010;84(3):1504-1512. https://doi.org/10.1128/JVI.02029-09

8. Gooz M. ADAM-17: the enzyme that does it all. Crit Rev Biochem Mol. 2010;45(2):146 - 169. https://doi. org/10.3109/10409231003628015

9. Sahin AR, Erdogan A, Agaoglu PM, et al. 2019 Novel Coronavirus (COVID-19) outbreak: a review of the current literature. EJMO. 2020;4(1):1-7. https://doi. org/10.14744/ejmo.2020.12220

10. Casadevall A, Pirofski LA. The convalescent sera option for containing COVID-19. J Clin Ivest. 2020;130(4):1545-1548. https://doi.org/10.1172/ $\mathrm{JCl} 138003$

11. Cao YC, Deng QX, Dai SX. Remdesivir for severe acute respiratory syndrome coronavirus 2 causing COVID-19: an evaluation of the evidence. Travel Med Infect Dis. 2020;2:101647. https://doi.org/10.1016/j. tmaid.2020.101647

12. Kany S, Vollrath JT, Relja B. Cytokines in inflammatory disease. Int J Mol Sci. 2019;20(23):6008. https://doi. org/10.3390/ijms20236008

13. Fahey E, Doyle SL. IL-1 Family cytokine regulation of vascular permeability and angiogenesis. Front immunol. 2019;10:1426. https://doi.org/10.3389/ fimmu.2019.01426

14. Keshari RS, Jyoti A, Dubey M, et al. Cytokines induced neutrophil extracellular traps formation: implication for the inflammatory disease condition. PLOS ONE. 2012;7(10):48111. https://doi.org/10.1371/journal. pone. 0048111

15. Xu Z, Shi L, Wang $Y$, et al. Pathological findings of COVID-19 associated with acute respiratory distress syndrome. Lancet Respir. 2020;8:420-422. https://doi. org/10.1016/S2213-2600(20)30076-X 
16. Moss ML, Minond D. Recent Advances in ADAM17 research: a promising target for cancer and inflammation. Mediators of Inflamm. 2017;3:1-21. https://doi.org/10.1155/2017/9673537

17. Pang J, Wang MX, Ang LYH, et al. Potential rapid diagnostics, vaccine and therapeutics for 2019 novel Coronavirus (2019-nCoV): A systematic review. J Clin Med. 2020;9(3):623. https://doi.org/10.3390/ jcm9030623

18. Sekaly RPJ. The failed HIV Merck vaccine study: a step back or a launching point for future vaccine development? J Exp Med. 2008;21(205):7-12. https:// doi.org/10.1084/jem.20072681

19. Zhang C, Zhou D. Adenoviral vector-based strategies against infectious disease and cancer. Hum Vaccine Immunother. 2016;12(8):2064-2074. https://doi.org $/ 10.1080 / 21645515.2016 .1165908$

20. Meiklejohn, G. Viral respiratory disease at lowry air force base in Denver, 1952-1982. J. Infect. Dis. 1983;148:775-784. https://doi.org/10.1093/ infdis/148.5.775

21. Moss ML, Minond D. Recent Advances in ADAM17 research: a promising target for cancer and inflammation. Mediators of Inflamm. 2017;3:1-21. https://doi.org/10.1155/2017/9673537

22. McMahon M, Arunkumar GA, Liu WC, et al. Vaccination with viral vectors expressing chimeric hemagglutinin, $\mathrm{np}$ and $\mathrm{m} 1$ antigens protects ferrets against influenza virus challenge. Front Immunol. 2019;10:2005. https:// doi.org/10.3389/fimmu.2019.02005

23. Sebastian $S$, Lambe T. Clinical advances in viral-vectored influenza vaccine. Vaccines. 2018;6(2):29. https://doi. org/10.3390/vaccines6020029

24. Zust R, Barragan LC, Kuri T, et al. Coronavirus nonstructural protein 1 is a major pathogenicity factor: implications for the rational design of coronavirus vaccines. PLoS Pathog. 2007;3(8):109. https://doi. org/109. 10.1371/journal.ppat.0030109

25. Lei J, Kusov $\mathrm{Y}$, Hilgenfeld R. Nsp3 of coronaviruses: structures and functions of a large multi-domain protein. Antiviral Res. 2018;149:58-74. https://doi. org/10.1016/j.antiviral.2017.11.001

26. Salinas LV, Rodriguez AV, Rodriguez LL, Borca MV. The role of interleukin 6 during viral infections. Front Microbiol. 2019;10:1057. https://doi.org/10.3389/ fmicb.2019.01057

27. Du L, Kou Z, Ma C, et al. A truncated receptorbinding domain of MERS-CoV spike protein potently inhibits MERS-CoV infection and induces strong neutralizing antibody responses: implication for developing therapeutics and vaccines. PLoS One. 2013;8(12):81587. https://doi.org/10.1371/journal. pone.0081587

28. Ulmer JM, Deck RR, DeWitt CM, Friedman A, Donnelly JJ, Liu MA. Protective immunity by intramuscular injection of low doses of influenza virus DNA vaccines. Vaccine. 1994;12(16):1541-1544. https:// doi.org/10.1016/0264-410x(94)90081-7

29. Ghaffarifar F, Jafarimodrek M, Vazini H, Sharifi Z, Dalimi A, Dayer MS. Assessment of DNA vaccine encoding Toxoplasma gondii microneme complete gene and IL-12 as adjuvant in BALB/c mice. Iran J Basic Med Sci.
2019;22(8):901-907.

30. Paules $\mathrm{Cl}$, Marston HD, Fauci AS. Coronavirus infections - more than just the common cold. JAMA, 2020; 323: 707-708. https://doi.org/10.1001/jama.2020.0757

31. See RH, Roper RL, Brunham RC. Rapid response research - SARS Coronavirus vaccines and application of processes to other emerging infectious diseases. Curr Immunol Rev. 2005;1(2):185-200. https://doi. org/10.2174/1573395054065106

32. Ahmed SF, Quadeer AA, McKay MR. Preliminary identification of potential vaccine targets for the COVID-19 Coronavirus (SARS-CoV-2) based on SARSCoV immunological studies. Viruses. 2020;25(12):254. https://doi.org/10.3390/v12030254

33. Salinas LV, Rodriguez AV, Rodriguez LL, Borca MV. The role of interleukin 6 during viral infections. Front Microbiol. 2019;10:1057. https://doi.org/10.3389/ fmicb.2019.01057

34. Du L, Kou Z, Ma C, et al. A truncated receptor-binding domain of MERS-CoV spike protein potently inhibits MERS-CoV infection and induces strong neutralizing antibody responses: implication for developing therapeutics and vaccines. PLoS One. 2013;4(8):81587. https://doi.org/10.1371/journal.pone.0081587

35. Dhama K, Sharun K, Tiwari R, et al. COVID-19, an emerging coronavirus infection: advances and prospects in designing and developing vaccines, immunotherapeutics, and therapeutics. Hum Vaccine Immunother. 2020;18:1-7. https://doi.org/10.1080/2 1645515.2020.1735227

36. Lin K, Roosinovich E, Ma B, Hung CF, Wu TC. Therapeutic HPV DNA vaccines. Immunol Res. 2010;47(1-3):86112. https://doi.org/10.1007/s12026-009-8141-6

37. Yellela SRV, Powers DN, Angart $P$, et al. Purification and analytics of a monoclonal antibody from chinese hamster ovary cells using an automated microbioreactor system. Journal Vis Exp. 2018;589471: 1-10. https://doi.org/10.3791/58947

38. Zhou J, Wang W, Zhong Q, et al. Immunogenicity, safety, and protective efficacy of an inactivated SARS-associated coronavirus vaccine in rhesus monkeys. Vaccine. 2005;23(24):3202-3209. https:// doi.org/10.1016/j.vaccine.2004.11.075

39. Bolles $\mathrm{M}$, Deming $\mathrm{D}$, Long $\mathrm{K}$, et al. A double-inactivated severe acute respiratory syndrome Coronavirus vaccine provides incomplete protection in mice and induces increased eosinophilic proinflammatory pulmonary response upon challenge. J Virol. 2011;85(23):1220112215. https://doi.org/10.1128/JVI.06048-11

40. Yanga $Y$, Pengb $F$, Wangd $R$, et al. The deadly coronaviruses: the 2003 SARS pandemic and the 2020 novel coronavirus epidemic in China. J Autoimmun. 2020;109:102434. https://doi.org/10.1016/j. jaut.2020.102434

41. Huang C, Wang Y, Li X, et al. Clinical features of patients infected with 2019 novel coronavirus in Wuhan, China. Lancet. 2020;15(395):497-506. https://doi. org/10.1016/S0140-6736(20)30183-5

42. Chen N, Zhou M, Dong X, et al. Epidemiological and clinical characteristics of 99 cases of 2019 novel coronavirus pneumonia in Wuhan, China: a Descriptive Study. Lancet. 2020;15(395):507-513. https://doi. 
org/10.1016/S0140-6736(20)30211-7

43. Li Q, Guan X, Wu P, et al. Early transmission dynamics in wuhan, china, of novel coronavirus-infected pneumonia. N Eng J Med. 2020;382(13):1199-1207. https://doi.org/10.1056/NEJMoa2001316

44. Purchase HG, Okazaki W, Burmester BR. Field trials with the herpes virus of turkeys (HVT) strain FC126 as a vaccine against marek's disease. Poult Sci. 1971;50(3):775- 783. https://doi.org/10.3382/ ps. 0500775

45. Palya V, Kiss I, Tatar KT, et al. Advancement in vaccination against Newcastle disease: recombinant HVT NDV provides high clinical protection and reduces challenge virus shedding with the absence of vaccine reactions. Avian Dis. 2012;56(2):282-287. https://doi. org/10.1637/9935-091511-Reg.1

46. Kutzler MA, Weiner DB. DNA vaccines: ready for prime time? Nat Rev Genet. 2008;9(10):776-88. https://doi. org $/ 10.1038 / \mathrm{nrg} 2432$

47. Jeurissen $\mathrm{SH}$, Janse EM, Lehrbach PR, Haddad EE, Avakian A, Whitfill CE. The working mechanism of an immune complex vaccine that protects chickens against infectious bursal disease. Immunology. 1998;95(3):494-500. https://doi.org/10.1046/j.13652567.1998.00617.x

48. Cazaban C, Rietema RMW, Wit JJD, Palya V, Gardin Y. Field assessment of an immune-complex infectious bursal disease vaccine in chicks born to non-hyperimmunized broiler breeders. IJVSAH. 2018;6(3):302.
49. Chen L, Xiong J, Bao L, Shi Y. Convalescent plasma as a potential therapy for COVID-19. Lancet Infect Dis, 2020;20(4):398-400. https://doi.org/10.1016/ S1473-3099(20)30141-9

50. Saiada F, Eldemery F, Zegpi RA, et al. Early Vaccination of Chickens Induces Suboptimal Immunity Against Infectious Bronchitis Virus. Avian Dis. 2019;63(1):38 - 47. https://doi.org/10.1637/11951-081418-Reg.1

51. Karimi V, Mohammadi $P$, Ghalyanchilangeroudi A, et al. Including 793/b type avian infectious bronchitis vaccine in 1-day-old chicken increased the protection against QX genotype. Trop Anim Health Prod. 2019;51(3):629-635. https://doi.org/10.1007/s11250018-1730-4

52. Ennaji Y, Khataby K, Ennaji MM. Infectious bronchitis virus in poultry: molecular epidemiology and factors leading to the emergence and reemergence of novel strains of infectious bronchitis virus. Emerging and Reemerging Viral Pathogens. 2020;1:31-44. https:// doi.org/10.1016/B978-0-12-814966-9.00003-2

53. Awad F, Hutton S, Forrester A, Baylis M, Ganapathy $K$. Heterologous live infectious bronchitis virus vaccination in day-old commercial broiler chicks: clinical signs, ciliary health, immune responses and protection against variant infectious bronchitis viruses. Avian Pathol. 2016;45(2):169-77. https://doi.org/10.1 080/03079457.2015.1137866

54. Chalumeau HP. Vaccine manufacture at the time of a pandemic influenza. Eur J Epidemiol. 1994;10(1):48790. https://doi.org/10.1007/bf01719684 